\title{
Quantum and tempo effects of changes during the demographic transition: classification of world sub-regions and selected countries
}

\author{
Marta Mustafina*
}

Charles University, Faculty of Science, Department of Demography and Geodemography, Prague, Czechia

* Corresponding author: marta_mustafina@yahoo.com

\begin{abstract}
The development patterns of both historical and contemporary demographic transitions are essential in understanding the outcomes of age structure changes among the countries. Existing literature analyzing demographic transition as a precursor to population ageing does not classify countries or regions worldwide by the scale and dynamics of those processes. The aim of this paper is to identify and describe the differentiation of quantum and tempo effects of changes taking place during the demographic transition through classification of sub-regions and selected countries worldwide. The results of this research, based on the historical vital statistics starting from as far as 1736 and future projections until 2100, feature how sub-regions and selected countries in the world are differentiated in terms of the scale and dynamics of the demographic transition process. The analysis reveals the fact that majority of sub-regions in the world tend(ed) to undergo long transitions lasting over 70 years, though contemporary demographic transitions demonstrate higher intensity and higher maximal rates of natural increase. African sub-regions are expected to experience relatively long processes of declining birth and death rates and estimated to complete their demographic transition in 90 years on average. The fastest processes, however, are observed in South America and Eastern Asia where some countries like China, for instance, completed their transitions in just 50 years. The scale and dynamics of demographic transition processes can serve as the ground for further research of challenges and development opportunities resulting from ageing societies during consequent post-transitional stages.
\end{abstract}

\section{KEYWORDS}

demographic transition; tempo; quantum; world; sub-regions

Received: 9 October 2019

Accepted: 29 January 2020

Published: 27 March 2020

Mustafina, M. (2020): Quantum and tempo effects of changes during the demographic transition: classification of world sub-regions and selected countries. AUC Geographica 55(1), 15-26

https://doi.org/10.14712/23361980.2020.3

(C) 2020 The Author. This is an open-access article distributed under the terms of the Creative Commons Attribution License (http://creativecommons.org/licenses/by/4.0). 


\section{Introduction}

Demographic transition is perhaps one of the most prominent events of population development in the modern history of mankind. Before the demographic transition that started in Europe during the end of the 18th century the length of human life was short with high fertility and mortality resulting in slow growth and young population (Dyson 2010). The first real explosion of population growth occurred during the Industrial Revolution and cultural advancement of the human society. That was the force that encouraged a remarkable population growth which spread around the world as a result of migration. It was for the very first time in history when it became possible to refer to the world's population as a single entity reacting to one dynamic process but with a different extent (Davis 1945).

Every country in the world at some point is affected by the demographic transition. It is a process of transformation of demographic patterns manifested by the changes in the levels of mortality, fertility and the age structure of individual populations (Pavlik 1980). The demographic transition has distinctive outsets and developments in different countries resulting in the process of population ageing. Existing literature analyzing demographic transition as a precursor to population ageing does not classify countries or regions worldwide by the scale and dynamics of those processes. Most of the literature examines current stages of the demographic transition in certain countries or the transition processes in some countries that have been completed. This research attempts to identify and classify sub-regions and selected countries worldwide by quantum and tempo of their demographic transition processes. Population ageing will eventually knock at the door of each society and the demographic transition being the forerunner of the ageing process is a very important subject for analysis. It is essential to study the development patterns of both historical and contemporary demographic transitions which could shed light to the outcomes of age structure changes among the countries. The scope and dynamics of transition processes can serve as the ground for further studies of challenges and development opportunities resulting from ageing societies.

\section{Background}

Also called as "demographic revolution", it is referred to as "demographic transition" by most of the authors. In classic literature, Frank Notestein is considered to be the one who first coined the term "demographic transition" (Rowland 2003). Rowland, referring to Notestein as the originator of the demographic transition theory distinguishes the classical pattern of the transition process through four main stages as follows: pre-transitional stage characterized by high birth and death rates; second stage of early transition when the death rates start to decline while birth rates remain high resulting in a rapid population growth; third stage of late transition when birth rates start to fall as well; and the post-transitional stage characterized by already low birth and death rates.

Pavlik (1980: 135), in his article "The Theory of Demographic Revolution", describes the demographic transition as "revolutionary and in the entire history of mankind unique quantitative-qualitative transformation of the nature of the demographic pattern, which in its outcome is most marked in changes in the levels of fertility, mortality and the age structure of individual populations". The onset of Industrial Revolution resulted in the first real explosion of population growth along with cultural advancement of the society. That was the force that initiated a remarkable population growth in Europe.

The main elements characterizing the demographic transition process including declining fertility and mortality are common across all countries worldwide, albeit the scope and dynamics are not. Dyson (2010) in his book "Population and Development: The Demographic Transition" provides comprehensive narration of the transition supported by empirical precision indicating the fact that the main processes of transition are influenced by the geographical, historical, socio-economic, cultural, institutional and other circumstances resulting in different timing and speed of their (processes) development in one country or another.

The first prerequisites of demographic transition emerged with mortality decline in Northern and Western Europe. Mortality started to drop towards the end of the 18th century but with a slower pace compared to more prominent decline that followed during the 19th as well as 20th century (Caldwell 2006; Dyson 2010). There exists some extent of difference in opinions regarding the causes of mortality declines at early stages. Davis (1945), for instance, put improved food supply at the forefront of the causes for mortality declines in Northern and Western Europe. He argued that more advanced agricultural techniques together with transportation and invention of machinery were part of the enhancing technological system which resulted in reduction of famine, undernourishment and susceptibility to deceases. Kirk (1996) gives credit to improved infrastructure along with rising incomes and development of the modern state which, on his opinion, were the most important grounds for alleviation of famine and also epidemics that led to decreasing mortality at early periods of transition. Later stages of declining mortality, however, were induced by medical revolution according to Kirk. Dyson (2010), on his turn, also emphasizes on the improvement in mortality as a result of "gradual emergence of the modern nation-state" and progress in reducing deaths from infectious diseases while arguing that the role of nutritional improvement in 
mortality alleviation at early stages of transition has been overestimated. According to Caldwell (2006), the Industrial Revolution was not only motivated by changes in production ways but the great advances in technical and scientific spheres together with the levels of education. All of the aforementioned causes resulted in the mortality decline to their own extent as the Age of Enlightenment was symbolized by the changes in all spheres including economic, social, political, and health aspects. A meaningful remark in this regard was made by Kingsley Davis stating that: "The decline in mortality was itself a cause as well as a result of the social transformation, because it made possible a longer and more efficient use of human energies" (Davis 1945: 5).

Reduction in marriage through its postponement or rise in the proportion of single women stand to be the causes of fertility decline while in the long run the main context lies in birth control (Dyson 2010). Landry (1987) argues that birth control use in France at the early stage of demographic transition was the result of people's strivings to retain the already achieved living standards. More children started to survive as a result of declines in child and, further on, infant mortality what lead to conscious control of fertility.

Back in 1986, Ron Lesthaege and Dirk van de Kaa have suggested the new concept of the second demographic transition (van de Kaa 2008). The new era of "individualistic family model" emerged in exchange for existing "bourgeois family model". Lesthaege (2010) noted that the first signs of the second demographic transition made appearance in the 1950s. The family that was considered to strengthen its positions as a social institution during the first transition started dissolving with manifestation of rising rates of divorce, abortion and cohabitation (van de Kaa 2008). The notion of the second demographic transition has been, however, criticized by some of the authors. Massimo Livi Bacci, for instance, stated that there is only one "demographic transition in world history" whose opinion was shared by Robert Cliquet and David Coleman according to whom it is merely a continuation or a "secondary feature", while Zdenek Pavlik and Alexander Vishnevsky favor a single "demographic revolution" (van de Kaa 2008; Lesthaege 2010).

\section{Data and methods}

Vital statistics prior 1950 used for the analysis of demographic transitions by sub-regions and selected countries was obtained mostly from Chesnais (1992). Crude birth and death rates along with rate of natural increase were the main indicators used in the analysis of vital statistics. The author analyzed 67 countries, 38 of which were less developed. Additional sources of vital series included the 2017 Revision of the World Population Prospects, Human Mortality Database and
Statistical Offices of Czechia, Japan and Sweden. Medium fertility projections have been used in the analysis of this paper.

The presented data from Chesnais (1992) for developed countries is of high quality unlike the data for developing countries. Inaccuracy of crude rates, however, differs by country where countries in advanced stages of transition - "on the point of returning to an equilibrium of feeble growth" - are less problematic in this regard (Chesnais 1992: 50). Among African countries more reliable and complete data is available for Northern Africa. Tunisia and Egypt are the two countries of the sub-region with the most reliable data according to Chesnais. Latin America presents comparatively accurate data that covers a larger period and is available for a substantial number of countries. The extent of availability and quality of data in Asia is somewhere between Africa and Latin America. Sri Lanka is one of the few Asian countries which has more or less complete civil registration for a relatively long period of time. On that account, the quality of historical vital series for developing countries used in this study may not be classified as completely precise.

It would have been more appropriate to use moving averages to smooth out vital series data but since the data post 1950 was mostly obtained from the World Population Prospects of the United Nations (UN) 2017 Revision, which is available only in averages over the five-year periods (from mid-year $(t)$ to mid-year $(t+5)$ centered on 1 January year $(t+3))$, it was not possible. As a result, moving averages method was not used in the analysis in order to avoid inconsistency.

There are different criteria for identifying the beginning and end points of demographic transition proposed by different authors. Criteria for delimiting the length of demographic transitions in this paper have been adopted from the methods proposed by Chesnais (1992). The beginning of the demographic transition $(T \alpha)$ is marked by the starting-point of a continuous decline in mortality rates (a decline which is not followed by a return to higher rates than those preceding the point from continuous decline). The end of the demographic transition ( $\mathrm{T} \omega$ ) is indicated by the point where natural increase returns (a period of at least five years) to the rate equal to or less than that of the period preceding the onset of the transition. Two additional points are also considered with regards to mortality: firstly, "mortality is not yet very low, which enables us to discount subsequent improvements and to recognize that the equilibrium at a given level is only provisional (as in certain European countries at the time of the 1930s depression)" and secondly, "mortality is very low, less than the level just cited; only then do we have the point at which the previous trend has been overcome" (Chesnais 1992: 14).

Classification of sub-regions and selected countries by the scale and dynamics of their demographic transitions was developed by the author based on 
the methods offered by Chesnais (1992). The countries were classified according to the maximal natural increase rate (NIR) and divided into three groups: less than $2 \%$ per year, $2-3 \%$ per year and over $3 \%$ per year. Countries and sub-regions were assigned to a particular NIR category based on the maximal rate of natural increase per year observed over at least a decade. The length of the transition exceeding 70 years was considered to be "long" and the duration of less than 70 years as "short".

\section{Demographic transition profiles around the world}

Historical and contemporary transitions differences are very important when it comes to comparing the phenomenon's tempo and quantum effects. The earlier transitions which have mostly been completed by today were rather gradual while the more recent transitions have faster processes.

The countries with vital rates illustrations below were chosen based on the pioneering stance in terms of the demographic transition process in the sub-regions they belong to. Countries of Western and Northern Europe being among the first to have undergone unprecedented declines of death and later on birth rates are considered to be the avant-garde of the demographic transition. One of the best examples of early transitions in Northern Europe is Sweden (Fig. 1). It is one of the few countries that has the luxury of continuous historical data availability and the transition model of Sweden almost exactly matches the classical demographic transition model (DTM).

Sweden's crude birth and death rates were fluctuating in the range of 25-35 per 1000 people during pre-transitional stage. Death rates started declining steadily in the beginning of the 19th century (around 1810-1815) while birth rates underwent continued fall starting from circa 1875 . The demographic transition in Sweden ended circa 1955-1960 when NIR fell to approximately 5 per 1000 which marked the starting point of its lasting return to the level less than that of the period preceding the onset date of the transition.

France was among the pioneers of demographic transition in Western Europe as well, though it has atypical model as NIR here was rather flat (Fig. 2). Birth and death rates fluctuated around 35-40 per 1000 persons at pre-transitional stage. Fertility decline originated very early compared to other countries of Western Europe. The onset of the transition process was marked around 1790-1795, which was an apparent starting point of a continuous mortality decline. France completed its demographic transition around 1970-1975 when fertility and mortality rates accounted for 17 births and 11 deaths per 1000, respectively.

In Central Europe, Czechia has the longest historical vital rates series available. That gives the possibility to trace the onset of the transition process. The beginning of the continuous decline in mortality was marked during 1865-1870 when the rate was registered at an average of 31.3 per 1000 and

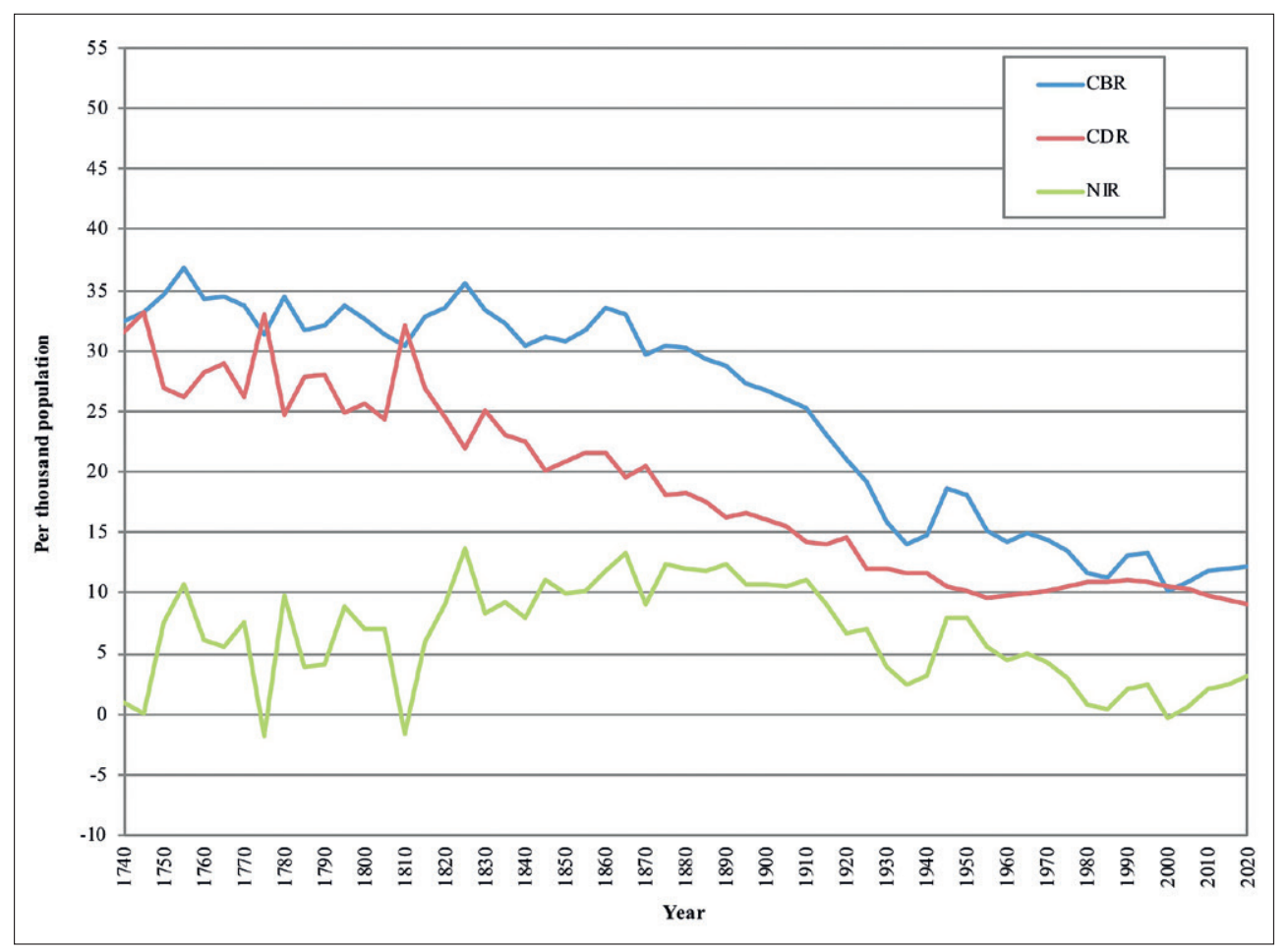

Fig. 1 Vital rates in Sweden, five-year periods, 1735-2100.

Sources: Statistics Sweden 2015, Chesnais 1992, United Nations 2017, and own calculations. 


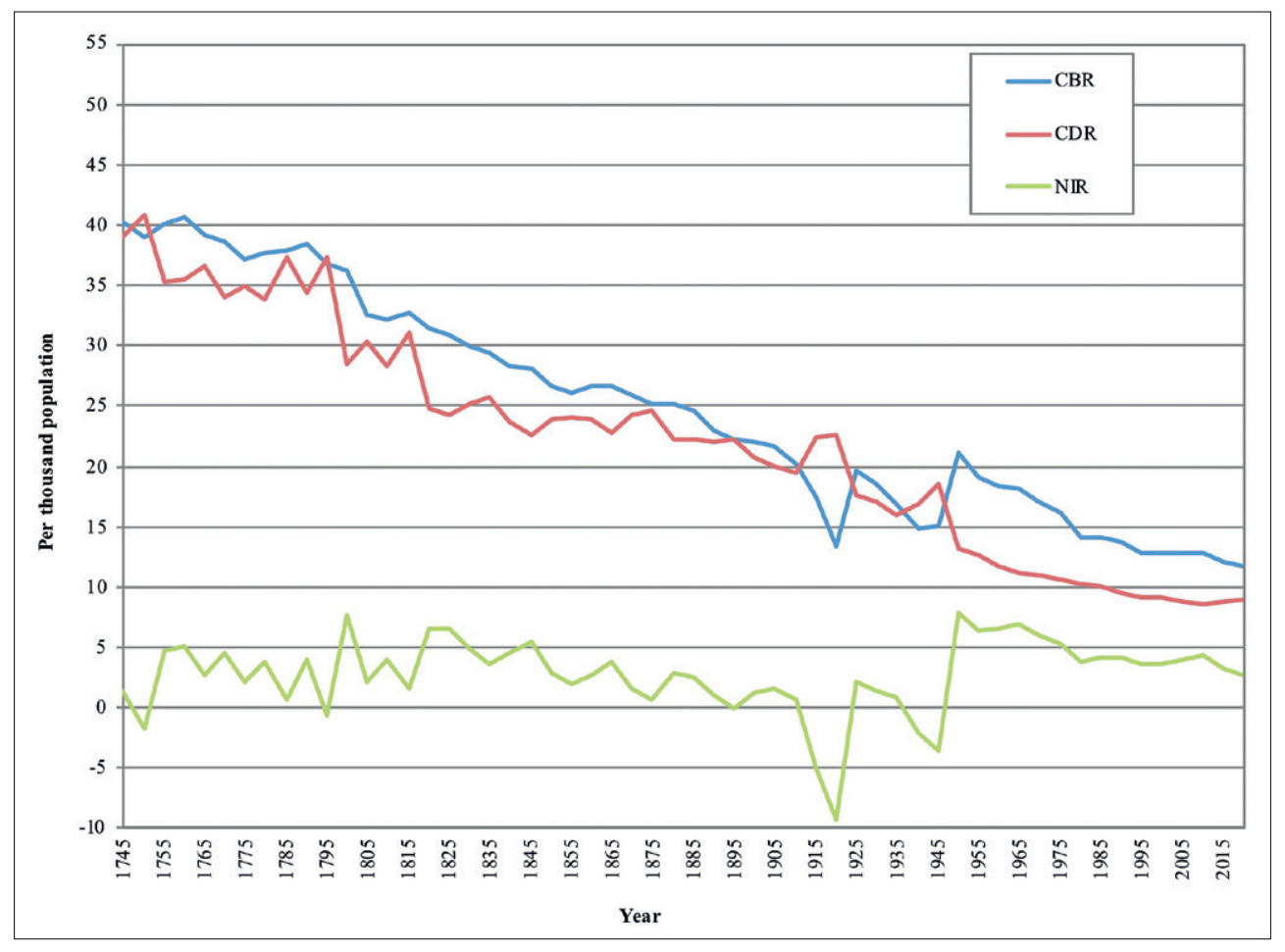

Fig. 2 Vital rates in France, five-year periods, 1740-2100.

Sources: Human Mortality Database, Chesnais 1992, United Nations 2017, and own calculations.

never returned to that level again (Fig. 3). Continuous decline in fertility started around 1870-1875 onwards when the last peak was registered at 39.6 births per 1000 people. The demographic transition here ended circa 1930-1935.
If we take a look at Japan, continuous fertility and mortality decline occurred around 1920-1925 here (Fig. 4). Very rapid fertility decline (from 30.1 to 18.0 births per 1000) took place during the period of 1950-1960 which was the outcome of the

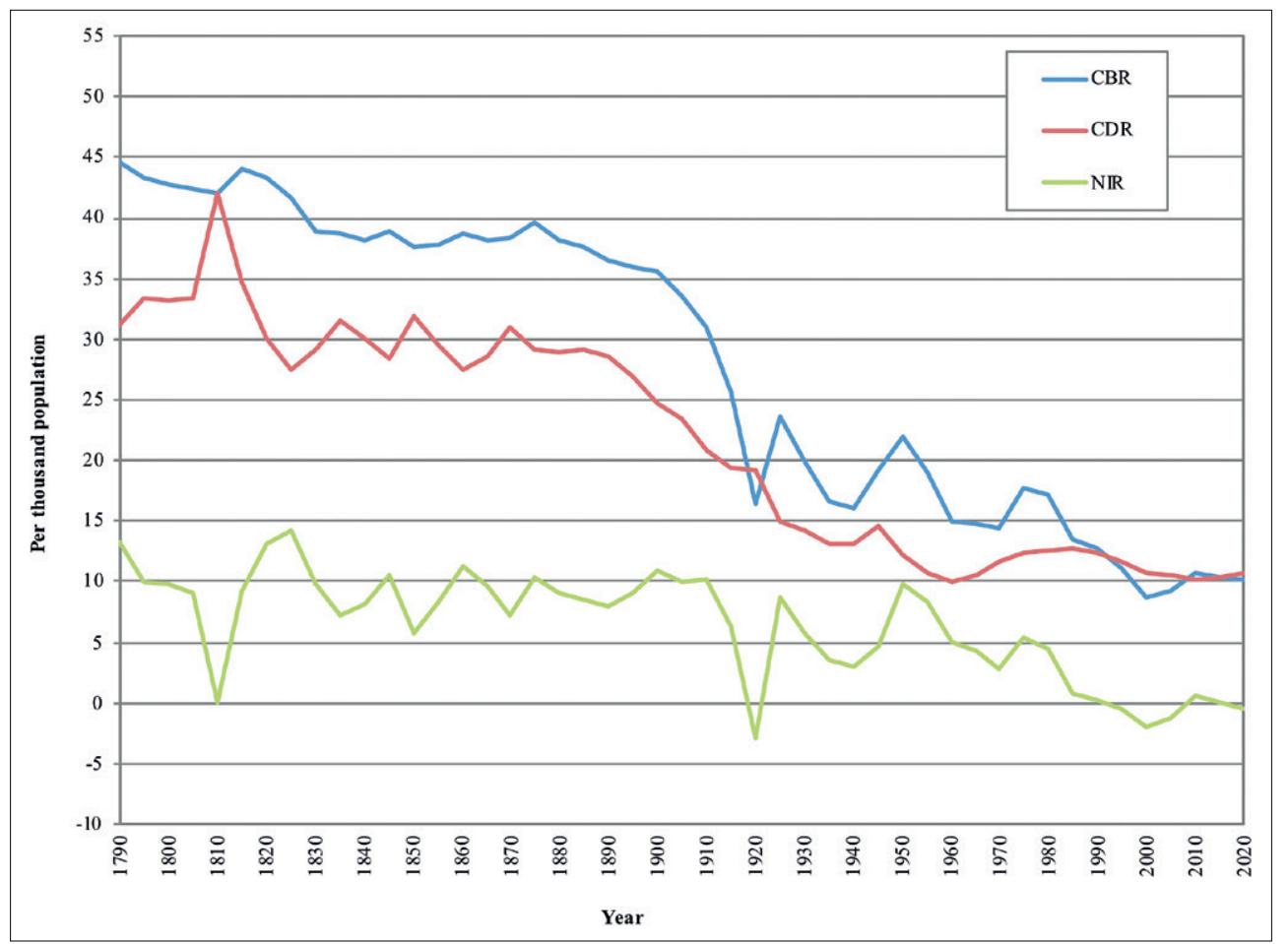

Fig. 3 Vital rates in Czechia, five-year periods, 1785-2100.

Sources: Czech Statistical Office 2015, United Nations 2017, and own calculations. 


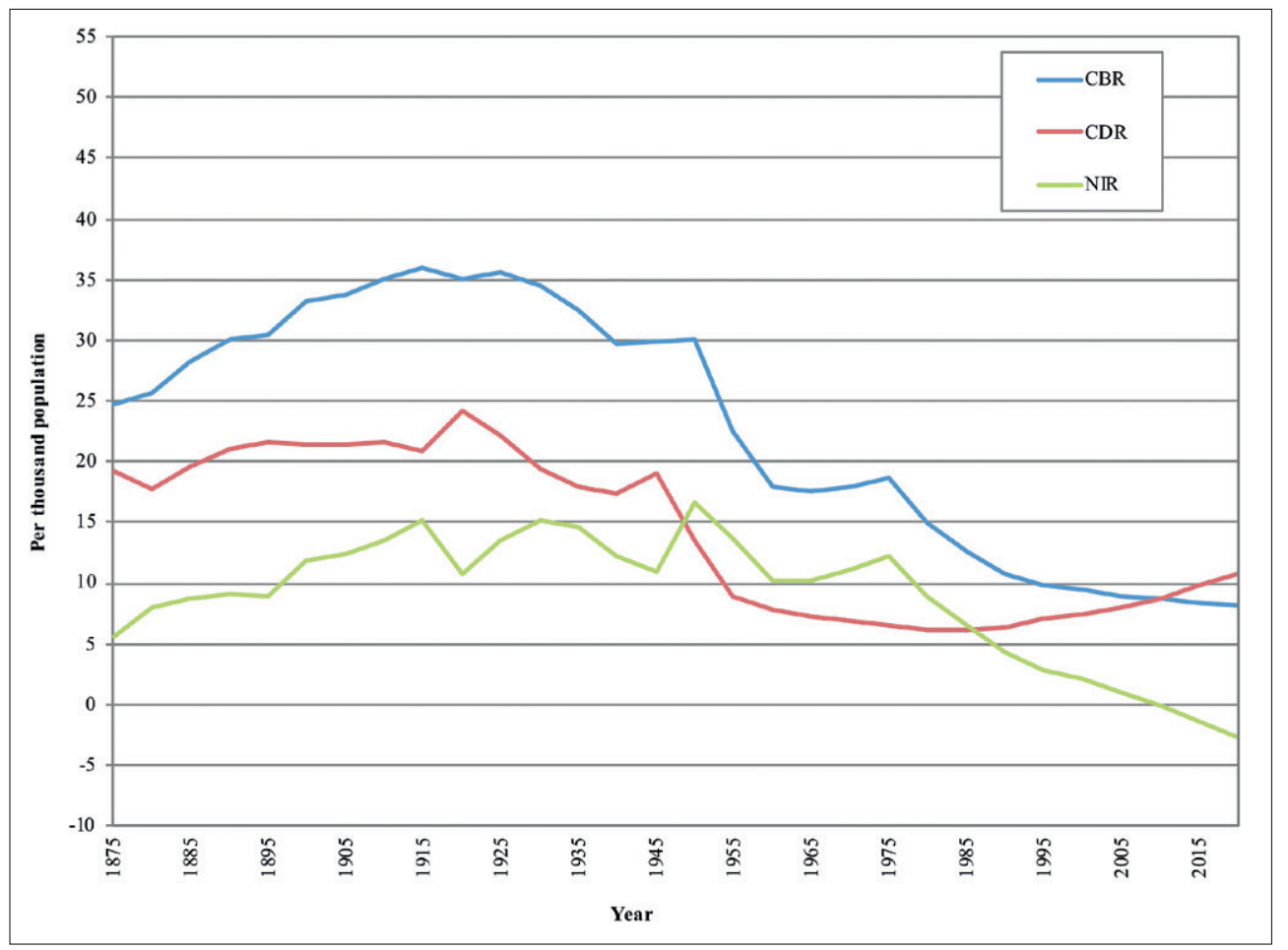

Fig. 4 Vital rates in Japan, five-year periods, 1870-2100.

Sources: Statistics Japan 1996, United Nations 2017, and own calculations.

eugenic population policy established in 1948 (Chesnais 1992). Adopted in 1948, "Eugenic Protection Law" aimed, as stated in the first Article, "to prevent birth of inferior descendants from the eugenic point of view, and to protect life and health of mother, as well" (Tsuchiya 1997). According to the law, sterilization was permitted with his/her and partner's consent. As noted by Tsuchiya, along with voluntary

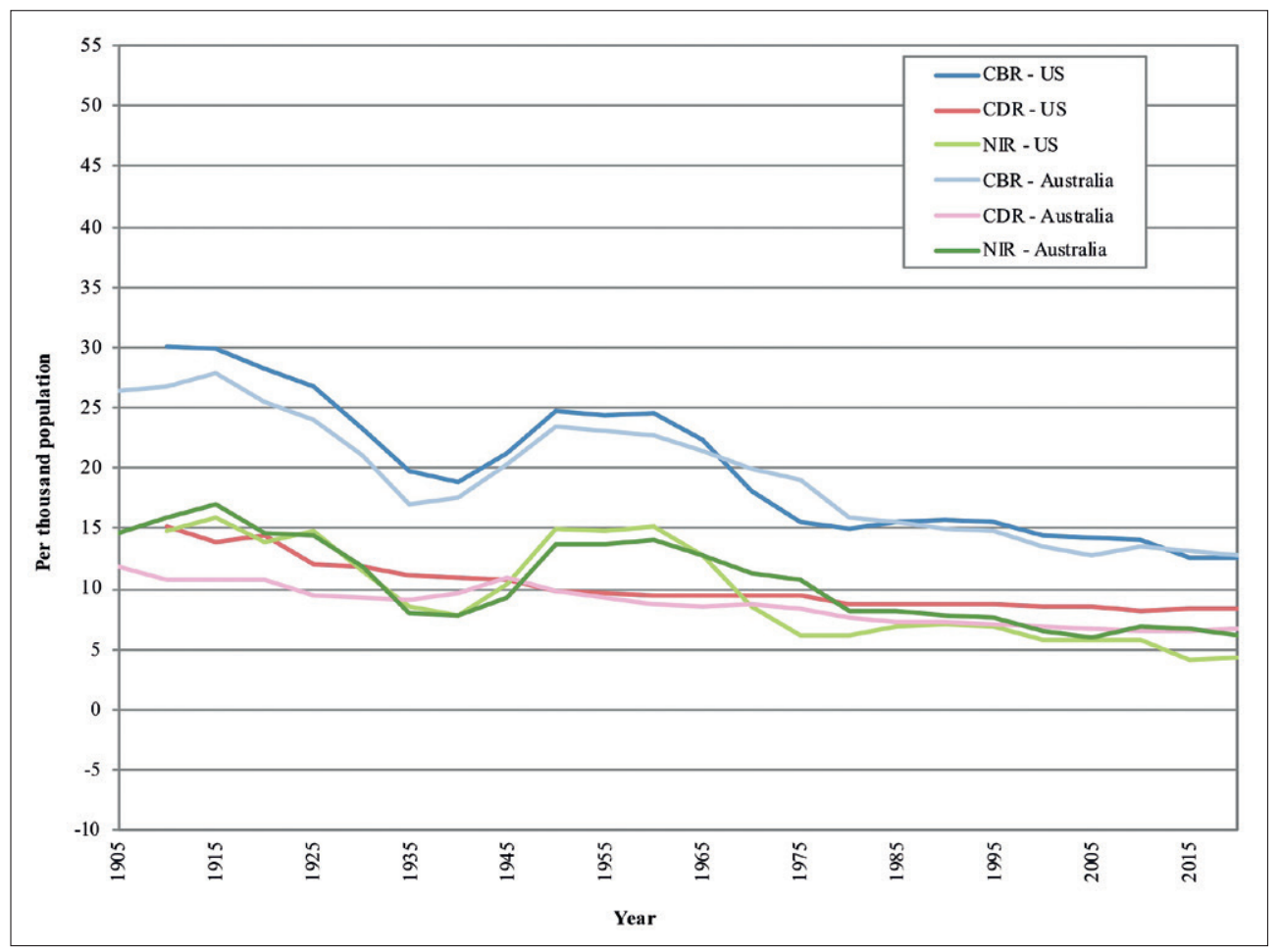

Fig. 5 Vital rates in the United States and Australia, five-year periods, 1900-2100.

Sources: Chesnais 1992, United Nations 2017, and own calculations. 


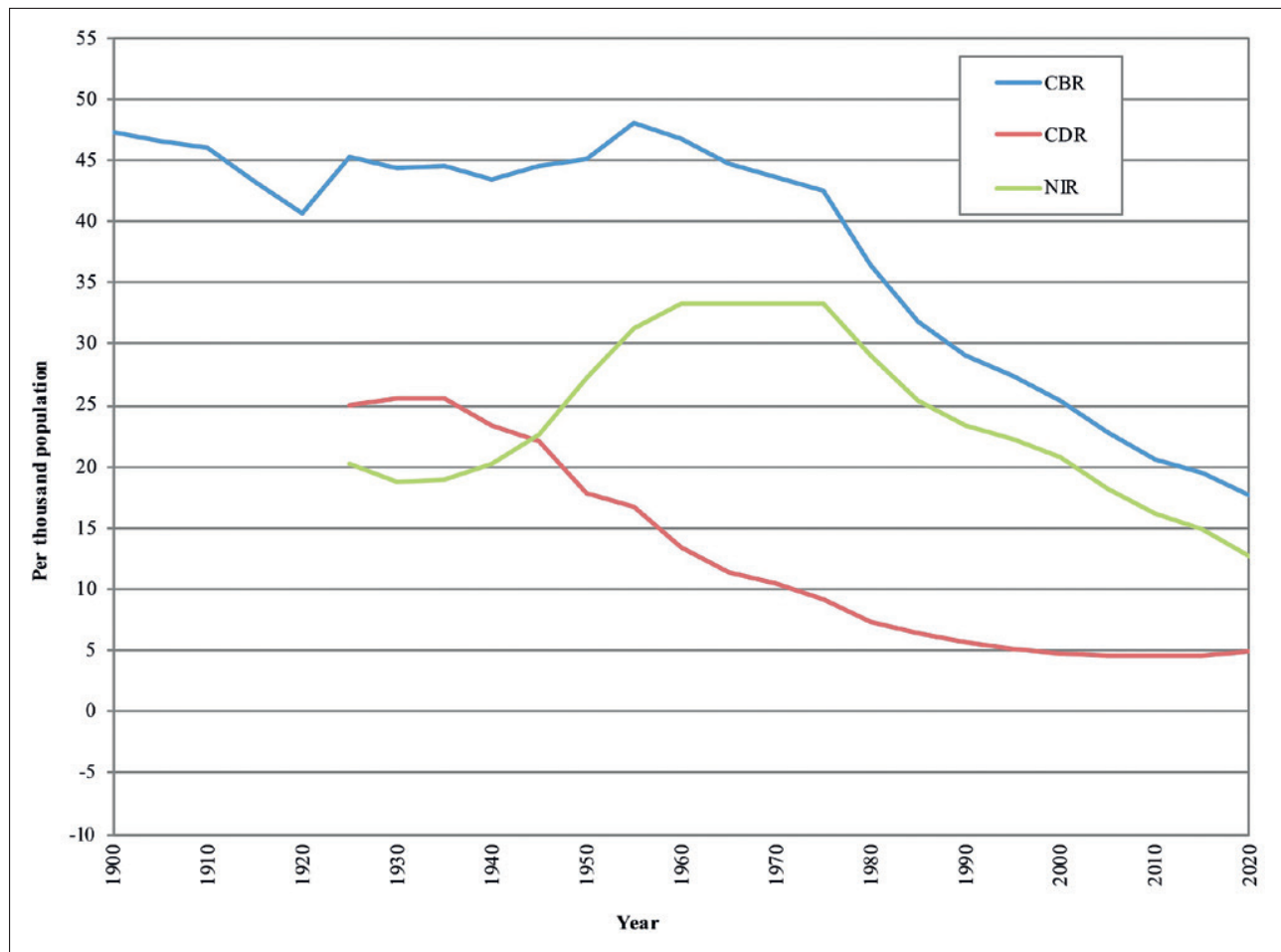

Fig. 6 Vital rates in Mexico, five-year periods, 1895-2100.

Sources: Chesnais 1992, United Nations 2017, and own calculations.

sterilization, the law also permitted involuntary sterilization of population with intellectual or mental disabilities during 1948-1996. The demographic transition ended around 1975-1980 in Japan.
Australia and the United States have been showing somewhat similar trend of vital rates since the beginning of the 20th century (Fig. 5). Historical vital series prior 1900 are not available which makes it difficult

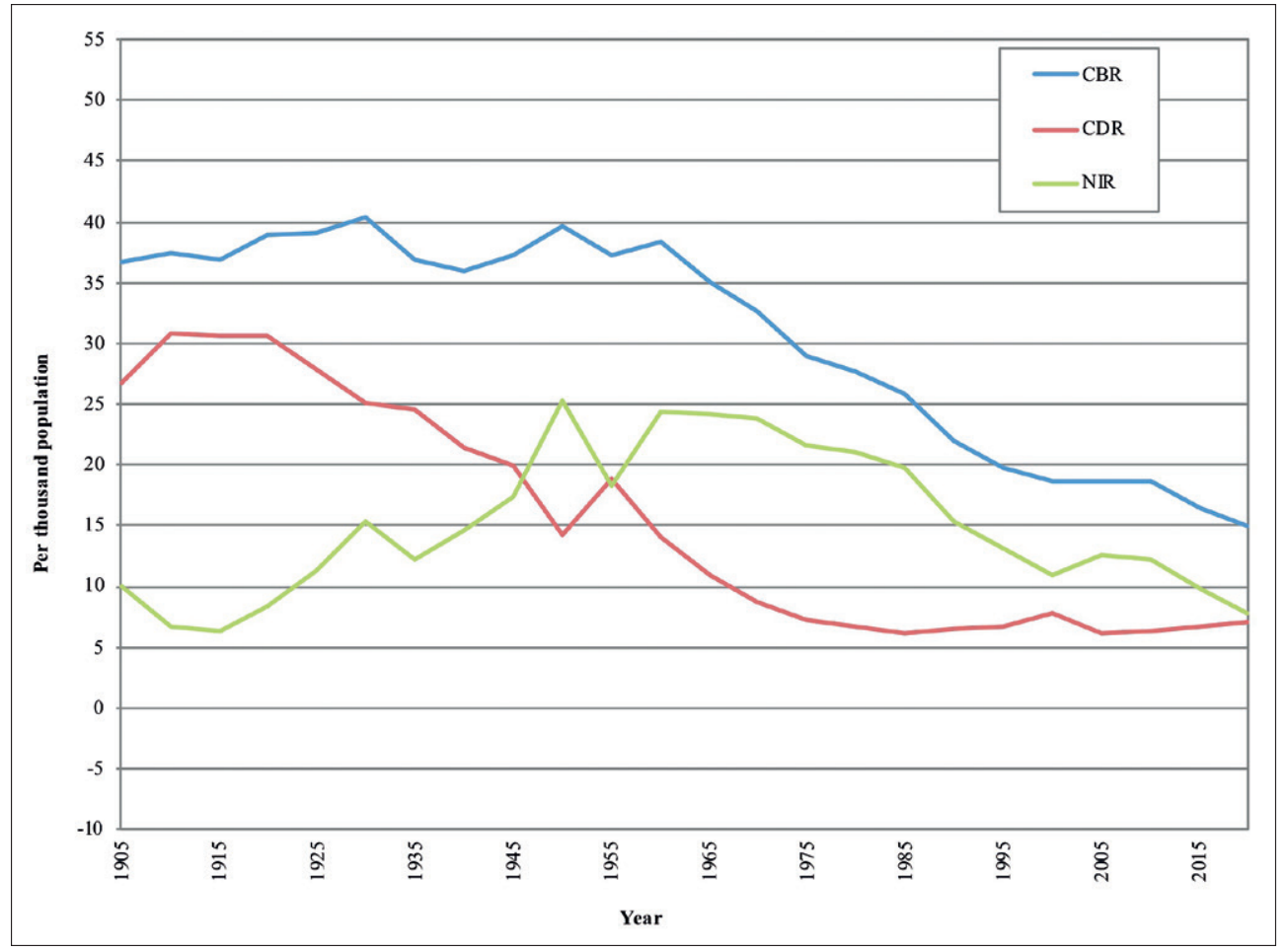

Fig. 7 Vital rates in Sri Lanka, five-year periods, 1900-2100.

Sources: Chesnais 1992, United Nations 2017, and own calculations. 


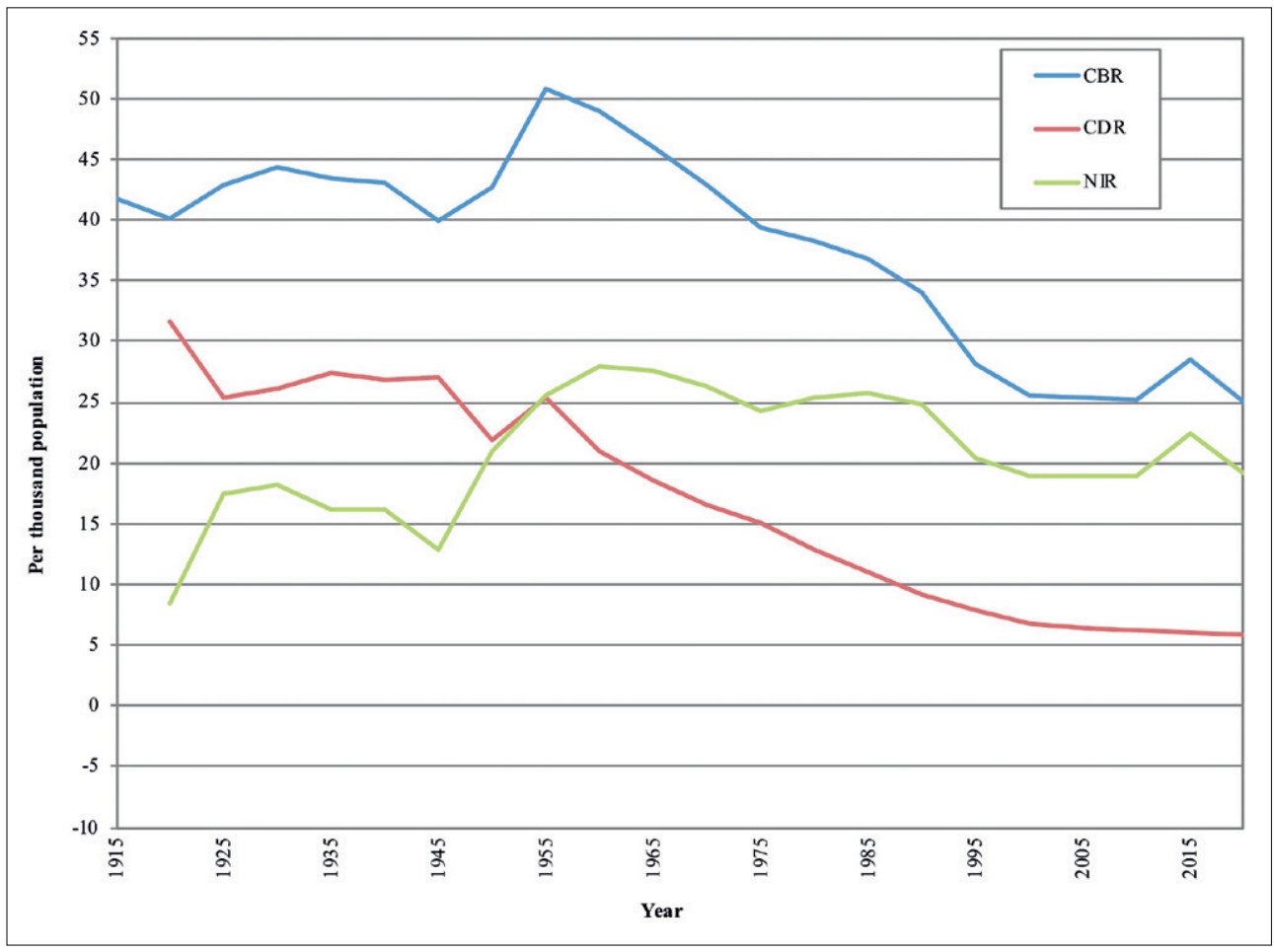

Fig. 8 Vital rates in Egypt, five-year periods, 1910-2100.

Sources: Chesnais 1992, United Nations 2017, and own calculations.

to determine the start of the demographic transition as mortality at that point is already low and fertility is decreasing.

As for the developing countries, vital rates in Mexico more or less follow the pattern of the classic DTM during the first stages (Fig. 6). The start of the continuous decline in mortality is observed during 1935-1940 followed by a decline in fertility around 1950-1955. Rapid decline of fertility starting from 1975-1980 resulted in a continuous slowdown of natural increase (United Nations 2017). Mexico has completed its demographic transition process during 2000-2005.

In Southern Asia, Sri Lanka was among the first countries to undergo the process of demographic transition. Death rate started to continuously decline as early as 1920-1925 when it decreased to 27.8 per 1000 without returning to that level again (Fig. 7). Uninterrupted and very steep decline in birth rates has been observed since 1960. The demographic transition process in Sri Lanka has just come to end during 2010-2015.

Egypt in Northern Africa has started its demographic transition right after the mid-20th century when mortality started to decrease followed by a fertility decline just a decade later (Fig. 8). Demographic transition in Egypt is expected to come to an end during 2015-2020 according to United Nations (2017) medium variant projections.

The demographic transition profiles of the developing countries as opposed to the developed ones have demonstrated two distinctive features including later decline in mortality and fertility and a more rapid progress with higher intensity.

\section{Results}

Being an inescapable phenomenon, demographic transition is going to eventually affect all of the countries worldwide. Vital processes around the world develop under different circumstances including various historical, social, cultural and economic conditions. As a result, there exists no single uniform model of demographic transition, though, all of the countries follow a particular pattern of transition stages where mortality decline precedes fertility decline.

To our knowledge, none of the existing literature analyzing demographic transition classifies countries or regions worldwide by the scale and dynamics of those processes. Most of the literature analyzes current stages of certain developing nations or completed transitions of few developed countries. Population projections provided by the UN within the 2017 Revision of the World Population Prospects present an opportunity to analyze the scale and dynamics of the demographic transition for developing countries.

Countries of Europe, Americas, Australia/New Zealand, and some Asian countries including China (inclusive of Hong Kong), Japan, Malaysia, Singapore, South Korea, North Korea and Cyprus have completed their demographic transition as of today. The 
other countries are still undergoing the demographic transition most of which are expected to terminate by mid-century apart from many African countries where the transition process will not be completed until a few decades later. (Chesnais 1992; United Nations 2017)

The analysis of the scale and dynamics of the demographic transitions in the world was based on identification and examination of the duration of those transitions by sub-regions as well as the weighted averages of maximal NIR per year observed during those periods. Lack of historical data series however hinders the analysis of some transitions within sub-regions. Apart from Africa, most of the sub-regions were analyzed mainly based on data provided in Chesnais (1992) which covers 67 countries worldwide. Hence, only countries with available data were grouped into sub-regions they are part of. Lists of included countries are indicated under the Tables.

European sub-regions along with Northern America and Australia/New Zealand are characterized by intermediary rates of natural increase not exceeding $2 \%$ with long transitions lasting on average from 70 years up to as long as over a century and a half. The oldest and longest demographic transitions have been observed in Europe, Northern America and Australia/New Zealand. Albania and France represent atypical cases (Tab. 1). Albania in comparison to Southern Europe has started its transition much later having the highest rates of natural increase of about $3.3 \%$ and shortest duration of the transition. France,

Tab. 1. Length and dynamics of demographic transitions in Europe, Northern America, and Australia/New Zealand.

\begin{tabular}{|l|l|c|}
\hline Sub-region/Country & Duration & $\begin{array}{c}\text { Maximal rate } \\
\text { of natural increase } \\
\text { per year (\%) }\end{array}$ \\
\hline Northern Europe & over 70 years & $1-2$ \\
\hline Western Europe & over 70 years & $1-2$ \\
\hline France & over 70 years & $<1$ \\
\hline Central Europe & over 70 years & $1-2$ \\
\hline Southern Europe & over 70 years & $1-2$ \\
\hline Albania & less than 70 years & $>3$ \\
\hline Eastern Europe & over 70 years & $1-2$ \\
\hline Northern America* & over 70 years & $1-2$ \\
\hline Australia/New Zealand* & over 70 years & $1-2$ \\
\hline
\end{tabular}

Notes: Northern Europe: Denmark, Finland, Norway, Sweden, and United Kingdom. Western Europe: Belgium, France, Netherlands, and Switzerland. Central Europe: Austria, Czechia, Germany, Hungary, and Poland. Southern Europe: Albania, Bosnia and Herzegovina, Croatia, TFYR Macedonia, Montenegro, Serbia, Slovenia, Greece, Italy, Portugal, and Spain. Eastern Europe: Belarus, Bulgaria, Romania, Russia, and Ukraine. Northern America: Canada and United States. * It is not possible to trace the onset of demographic transition in countries historically populated by immigrants due to data unavailability. The proposed lengths are approximate, based on calculations of Chesnais (1992) who used the estimations for life expectancy or infant mortality.

Sources: Chesnais 1992, United Nations 2017, and own calculations. in its turn, demonstrates the lowest rates of natural increase below $1 \%$ and the longest transition in the world.

Asian countries are substantially diverse in the aspects of maximal NIR and the duration of transitions (Tab. 2). Eastern Asia and South-Eastern Asia are the most heterogeneous in that sense. Therefore, countries from those sub-regions have been analyzed separately since grouped analysis would not produce adequate results. Japan, for instance, has the lowest maximal NIR of around 1.7\%. Hong Kong represents probably the shortest transition of around 40 years while having very high rates of natural increase above $3 \%$. China followed a similar pattern in terms of the beginning and duration of the demographic transition but with lower maximal NIR of approximately $2.7 \%$. Singapore also completed its transition process in 50 years like China but 20 years earlier and with much higher NIR. Mongolia, unlike other countries of Eastern Asia is undergoing relatively long transition which is expected to end around the year 2040. Southern Asia has been divided into two groups based on the differences in maximal rates of natural increase. Central Asian sub-region is characterized by very high NIR with the beginning of the demographic transition in the 1950s that is projected to last until circa 2030. Western Asia has been the last sub-region in Asia to commence with the transition process around the

Tab. 2. Length and dynamics of demographic transitions in Asian sub-regions and selected countries.

\begin{tabular}{|c|c|c|}
\hline Sub-region/Country & Duration & $\begin{array}{c}\text { Maximal rate } \\
\text { of natural increase } \\
\text { per year (\%) }\end{array}$ \\
\hline China & less than 70 years & $2-3$ \\
\hline Japan & less than 70 years & $1-2$ \\
\hline South and North Korea & over 70 years & $2-3$ \\
\hline Hong Kong & less than 70 years & $>3$ \\
\hline Mongolia & over 70 years & $2-3$ \\
\hline Central Asia & over 70 years & $>3$ \\
\hline Southern Asia I & over 70 years & $2-3$ \\
\hline Southern Asia II & over 70 years & $>3$ \\
\hline Sri Lanka & over 70 years & $2-3$ \\
\hline Afghanistan & over 70 years & $>3$ \\
\hline Singapore & less than 70 years & $>3$ \\
\hline Malaysia & over 70 years & $>3$ \\
\hline Philippines & over 70 years & $2-3$ \\
\hline Cyprus & over 70 years & $2-3$ \\
\hline Western Asia & over 70 years & $>3$ \\
\hline Yemen & over 70 years & $>3$ \\
\hline
\end{tabular}

Notes: Central Asia: Uzbekistan, Turkmenistan, Kazakhstan, and Kyrgyzstan. Southern Asia I: India, Bhutan, Nepal, Pakistan, and Sri Lanka. Southern Asia II: Afghanistan, Bangladesh, Iran, and Maldives. Western Asia: Bahrain, Cyprus, Oman, Saudi Arabia, Palestine, Syria, and Yemen.

Sources: Bolormaa 2011, Chesnais 1992, Kim 1994, United Nations 2017, and own calculations. 
1960 s with a projected end around the 2030s. Yemen being an extreme case with maximal NIR above $4 \%$ started undergoing the process only around the year 1980. Sri Lanka, as mentioned above, has an atypical model for its region where the process initiated much earlier around 1920 with relatively high NIR.

American sub-regions (excluding Northern America) experienced much higher NIR and shorter durations of transitions lasting on average 60 to 70 years (Tab. 3). Despite the fact that American sub-regions started to undergo declining mortality and fertility rates much later than the European ones, they have already reached the culmination of the process by today. To distinguish relatively homogenous groups of countries, South America has been split into two groups because of rather substantial differences in maximal NIR. Argentina is one of the exceptions in the region that underwent a century long transition having followed the trait of the European transition model. Caribbean countries experienced the shortest transitions in the region, lasting around 60 years on average with an exception of Jamaica, for instance, which had longer transition process and higher maximal NIR.

Tab. 3 Length and dynamics of demographic transitions in American sub-regions and selected countries.

\begin{tabular}{|l|l|c|}
\hline Sub-region/Country & Duration & $\begin{array}{c}\text { Maximal rate } \\
\text { of natural increase } \\
\text { per year (\%) }\end{array}$ \\
\hline Central America & over 70 years & $>3$ \\
\hline South America I & less than 70 years & $2-3$ \\
\hline South America II & less than 70 years & $>3$ \\
\hline Argentina* & over 70 years & $1-2$ \\
\hline Caribbean & less than 70 years & $2-3$ \\
\hline Jamaica & over 70 years & $>3$ \\
\hline
\end{tabular}

Notes: Central America: Cost Rica, Mexico, Panama, and El Salvador. South America I: Argentina, Brazil, Chile, Ecuador, Peru, and Uruguay. South America II: Colombia, Venezuela, and Suriname.

Caribbean: Cuba, Jamaica, Puerto Rico, and Trinidad and Tobago.

* Ibid.

Sources: Chesnais 1992, United Nations 2017, and own calculations.

Africa is the last region to undergo the demographic transition process with relatively high maximal NIR (Tab. 4). Eastern and Middle Africa are expected to likely end their transition process by around 2060 having stared circa 1970. Western Africa illustrates the latest transition in the region that has started only around 1980 and is projected to end by approximately 2070 while Northern Africa should be the first African sub-region to complete its transition around the year 2030 .

Six main types of demographic transitions have been identified according to their duration (long transitions lasting over 70 years and short transitions less than 70 years respectively) and the maximal rate of natural increase (below 2\%, 2-3\% and over 3\%) (Tab. 5).
Tab. 4 Length and dynamics of demographic transitions in African sub-regions.

\begin{tabular}{|l|l|c|}
\hline Sub-region/Country & Duration & $\begin{array}{c}\text { Maximal rate } \\
\text { of natural increase } \\
\text { per year (\%) }\end{array}$ \\
\hline Northern Africa & over 70 years & $2-3$ \\
\hline Eastern Africa & over 70 years & $>3$ \\
\hline Middle Africa & over 70 years & $2-3$ \\
\hline Southern Africa & over 70 years & $2-3$ \\
\hline Western Africa & over 70 years & $2-3$ \\
\hline
\end{tabular}

Notes: African sub-regions are represented by all of the countries belonging to those areas based on UN classification.

Sources: United Nations 2017 and own calculations.

Tab. 5 Classification of the scale and dynamics of the demographic transitions in the world by sub-regions and selected countries.

\begin{tabular}{|c|c|}
\hline $\begin{array}{l}\text { Type I - Long low transition } \\
\text { Duration: longer than } 70 \text { years } \\
\text { Rate of natural increase }(\%):<2\end{array}$ & $\begin{array}{l}\text { Type II - Short low transition } \\
\text { Duration: shorter than } 70 \text { years } \\
\text { Rate of natural increase }(\%):<2\end{array}$ \\
\hline $\begin{array}{l}\text { Northern Europe } \\
\text { Western Europe } \\
\text { Central Europe } \\
\text { Southern Europe } \\
\text { Eastern Europe } \\
\text { Northern America } \\
\text { Argentina (South America) } \\
\text { Australia/New Zealand }\end{array}$ & Japan (Eastern Asia) \\
\hline $\begin{array}{l}\text { Type III - Long intermediate } \\
\text { transition } \\
\text { Duration: longer than } 70 \text { years } \\
\text { Rate of natural increase (\%): 2-3 }\end{array}$ & $\begin{array}{l}\text { Type IV - Short intermediate } \\
\text { transition } \\
\text { Duration: shorter than } 70 \text { years } \\
\text { Rate of natural increase (\%): 2-3 }\end{array}$ \\
\hline $\begin{array}{l}\text { South and North Korea (Eastern } \\
\text { Asia) } \\
\text { Mongolia (Eastern Asia) } \\
\text { Southern Asia I } \\
\text { Sri Lanka (Southern Asia) } \\
\text { Philippines (South-Eastern Asia) } \\
\text { Cyprus (Western Asia) } \\
\text { Northern Africa } \\
\text { Middle Africa } \\
\text { Southern Africa } \\
\text { Western Africa }\end{array}$ & $\begin{array}{l}\text { South America I } \\
\text { Caribbean } \\
\text { China (Eastern Asia) }\end{array}$ \\
\hline $\begin{array}{l}\text { Type V - Long high transition } \\
\text { Duration: longer than } 70 \text { years } \\
\text { Rate of natural increase }(\%):>3\end{array}$ & $\begin{array}{l}\text { Type VI - Short high transition } \\
\text { Duration: shorter than } 70 \text { years } \\
\text { Rate of natural increase }(\%):>3\end{array}$ \\
\hline $\begin{array}{l}\text { Central America } \\
\text { Jamaica and Trinidad and Tobago } \\
\text { (Caribbean) } \\
\text { Central Asia } \\
\text { Southern Asia II } \\
\text { Afghanistan (Southern Asia) } \\
\text { Malaysia (South-Eastern Asia) } \\
\text { Western Asia } \\
\text { Eastern Africa }\end{array}$ & $\begin{array}{l}\text { Albania (Southern Europe) } \\
\text { South America II } \\
\text { Hong Kong (Eastern Asia) } \\
\text { Singapore (South-Eastern Asia) }\end{array}$ \\
\hline
\end{tabular}

Sources: Author's own study based on data from Bolormaa 2011, Chesnais 1992, Kim 1994, and United Nations 2017.

The classification of sub-regions and selected countries by the scale and dynamics of transitions clearly depicts their homogeneity as well as heterogeneity based on vital rates development. Table 5 
shows that European sub-regions are quite homogeneous in terms of the period it took them to transition from high birth and death rates to low birth and death rates. Japan is perhaps the most unique case being the only country falling under the second type of short low transition as the process there lasted only around 65 years with considerably low NIR not exceeding $1.7 \%$. It is interesting to see that some countries of Central America, Central Asia, Western Asia and Eastern Africa belong to the same type of long and high transition. There are just a few countries that underwent short transition with intermediate and high maximal rates of natural increase around $2-3 \%$ and above $3 \%$ respectively.

The results of the analysis reveal the fact that majority of the sub-regions around the world tend to undergo long transitions lasting over 70 years. Even African contemporary transitions are expected to have relatively long processes of declining birth and death rates according to medium variant projections of United Nations (2017). The fastest processes are observed in Eastern Asia and South America.

\section{Conclusions}

This research paper has identified the demographic changes taking place during the transition process and classified the sub-regions and selected countries worldwide by quantum and tempo of the process. First, the demographic transitions by selected countries which were the pioneers of the process in the regions they belong to have been analyzed in detail. Then, the sub-regions and selected countries with atypical cases have been classified based on the quantum and tempo of their demographic transitions. The results show that the countries that have already completed their transition process until today include those of Europe, Americas, Australia/ New Zealand, and some countries from Asia including China (inclusive of Hong Kong), Japan, Malaysia, Singapore, South Korea, North Korea and Cyprus. The rest of the countries are still in the process most of which are expected to complete it by mid-century or even later. The analysis has also revealed the fact that the majority of the sub-regions in the world tend to undergo long transitions lasting over 70 years, but contemporary demographic transition processes have higher intensity with higher maximal rates of natural increase. France along with countries of Northern Europe experienced the longest historical transitions stretched over the period of approximately 150 years and over, which started as early as the end of the 18th and the very beginning of the 19 th century respectively. Even contemporary transitions in Africa are expected to have relatively long processes of declining birth and death rates according to UN medium variant projections where transitions are estimated to last for an average of 90 years.
The fastest processes are observed in Eastern Asia and South America. Suchwise, China and Singapore completed their transitions in just 50 years.

Demographic transition brings along inescapable changes in the age structures that lead to the ageing of population. The growth of the number and proportion of older persons started to accelerate towards the end of the 20th century as a result of a rapid increase that started in the developing world. The phenomenon of demographic transition followed by population ageing has to be perceived as an inevitable outcome of the progress our societies are going through.

\section{Acknowledgements}

This research was supported by the SVV project No. 260425 of the Grant Agency of Charles University.

\section{References}

Bolormaa, T. (2011): The Impact of Demographic Changes in the Development Policy of Mongolia. Paper presented at UNFPA Symposium on the Impact of Demographic Change in Thailand, Bangkok, 27-28 April.

Caldwell, J. C. (2006): Demographic Transition Theory. Dordrecht: Springer.

Chesnais, J. C. (1992): The Demographic Transition - Stages, Patterns, and Economic Implications. Oxford: Clarendon Press.

Czech Statistical Office (2015): Population - annual time series. [electronic resourse]. Czech Statistical Office. https://www.czso.cz/csu/czso/population_hd

Davis, K. (1945): The World Demographic Transition. Annals of the American Academy of Political and Social Science 237, 1-11, https://doi.org/10.1177 /000271624523700102.

Human Mortality Database. France. [electronic resourse]. Berkeley: University of California and Rostock: Max Planck Institute for Demographic Research. http:// www.mortality.org/cgi-bin/hmd/country.php?cntr =FRA\&level $=2$

Kim, D. S. (1994): The Demographic Transition in the Korean Peninsula, 1910-1990: South and North Korea Compared. Korea Journal of Population and Development 23(2), 131-155.

Kirk, D. (1996). Demographic Transition Theory. Population Studies 50(3), 361-387, https://doi.org/10.1080/00324 72031000149536.

Lesthaeghe, R. J. (2010): The Unfolding Story of the Second Demographic Transition. Michigan: University of Michigan (PSC Research Report No. 10-696).

Pavlik, Z. (1980): The Theory of Demographic Revolution. European Demographic Information Bulletin 11(4), 130-139, https://doi.org/10.1007/BF02917743.

Reher, D. S. (2004): The Demographic Transition Revisited as a Global Process. Population, Space and Place 10, 19-41, https://doi.org/10.1002/psp.313.

Rowland, D. T. (2003): Demographic Methods and Concepts. New York: Oxford University Press. 
Statistics Japan (1996): Population and Households. [electronic resource]. Tokyo: Statistics Bureau. http:// www.stat.go.jp/english/data/chouki/02.htm

Statistics Sweden (2015): Population Statistics. [electronic resource]. Stockholm: Statistics Sweden. http://www .scb.se/BE0101-EN/\#c_undefined

Tsuchiya, T. (1997): Eugenic Sterilizations in Japan and Recent Demands for Apology: A Report. [electronic resourse]. Newsletter of the Network on Ethics and Intellectual Disability 3(1), 1-4. http://www.lit.osaka -cu.ac.jp/user/tsuchiya/gyoseki/paper/JPN_Eugenics .html
United Nations (2017): World Population Prospects: The 2017 Revision. [electronic resource]. New York: Department of Economic and Social Affairs, Population Division. https://population.un.org/wpp/

United Nations (2015): World Population Ageing 2015. New York: Department of Economic and Social Affairs, Population Division. http://www.un.org/en /development/desa/population/publications/pdf /ageing/WPA2015_Report.pdf

van de Kaa, D. J. (2008): Demographic Transitions. Netherlands Interdisciplinary Demographic Institute (NIDI Working Paper No. 1). 